\title{
Trends in the sources and sinks of carbon dioxide
}

\author{
Corinne Le Quéré, Michael R. Raupach, Josep G. Canadell, Gregg Marland et al.*
}

\begin{abstract}
Efforts to control climate change require the stabilization of atmospheric $\mathrm{CO}_{2}$ concentrations. This can only be achieved through a drastic reduction of global $\mathrm{CO}_{2}$ emissions. Yet fossil fuel emissions increased by $29 \%$ between 2000 and 2008 , in conjunction with increased contributions from emerging economies, from the production and international trade of goods and services, and from the use of coal as a fuel source. In contrast, emissions from land-use changes were nearly constant. Between 1959 and 2008, $43 \%$ of each year's $\mathrm{CO}_{2}$ emissions remained in the atmosphere on average; the rest was absorbed by carbon sinks on land and in the oceans. In the past 50 years, the fraction of $\mathrm{CO}_{2}$ emissions that remains in the atmosphere each year has likely increased, from about $40 \%$ to $45 \%$, and models suggest that this trend was caused by a decrease in the uptake of $\mathrm{CO}_{2}$ by the carbon sinks in response to climate change and variability. $\mathrm{Changes}$ in the $\mathrm{CO}_{2}$ sinks are highly uncertain, but they could have a significant influence on future atmospheric $\mathrm{CO}_{2}$ levels. It is therefore crucial to reduce the uncertainties.
\end{abstract}

A tmospheric measurements of $\mathrm{CO}_{2}$ concentration are highly precise and provide an accurate, reliable measure of the increase of $\mathrm{CO}_{2}$ in the atmosphere every year ${ }^{1}$. Yet these measurements cannot at present be used to verify global $\mathrm{CO}_{2}$ emissions estimated from energy data, because the uptake of $\mathrm{CO}_{2}$ by the land and ocean $\mathrm{CO}_{2}$ sinks are not quantified with high enough accuracy. Understanding the difference in amount between anthropogenic $\mathrm{CO}_{2}$ emissions and changes in atmospheric $\mathrm{CO}_{2}$ concentration requires good estimates of the sinks and good attribution of the causes of changes, both for the emissions and for their partitioning between the natural reservoirs.

Global $\mathrm{CO}_{2}$ emissions and their partitioning between the atmosphere and the land and ocean $\mathrm{CO}_{2}$ sinks can be established using a wide range of geophysical and economic data. We have constructed a global $\mathrm{CO}_{2}$ budget for each year during 1959-2008 and analysed the underlying drivers of each component. The global increase in atmospheric $\mathrm{CO}_{2}$ was determined directly from measurements. $\mathrm{CO}_{2}$ emissions from fossil fuel combustion were estimated on the basis of countries' energy statistics. $\mathrm{CO}_{2}$ emissions from land-use change (LUC) were estimated using deforestation and other land-use data, fire observations from space, and assumptions on the carbon density of vegetation and soils and the fate of carbon. The time evolution of the land and ocean $\mathrm{CO}_{2}$ sinks, however, cannot be estimated directly from observations. For these terms, we used state-of-the-art models on which we imposed the observed meteorological conditions of the past few decades. The resulting global $\mathrm{CO}_{2}$ budget provides insight into the global carbon cycle and the emerging trends.

\section{Fossil fuel $\mathrm{CO}_{2}$ emissions}

$\mathrm{CO}_{2}$ emissions from fossil fuel combustion, including small contributions from cement production and gas flaring, were $8.7 \pm 0.5 \mathrm{Pg} \mathrm{C} \mathrm{yr}^{-1}$ in 2008 , an increase of $2.0 \%$ on $2007,29 \%$ on 2000 and $41 \%$ above emissions in 1990 (Supplementary Table 1; see Methods). Emissions increased at a rate of $3.4 \% \mathrm{yr}^{-1}$ between 2000 and 2008, compared with $1.0 \% \mathrm{yr}^{-1}$ in the 1990s (Fig. 1). Emissions continued to track the average of the most carbonintensive family of scenarios put forward by the Intergovernmental Panel on Climate Change ${ }^{2,3}$ (IPCC; scenario A1FI in Fig. 1a). Since 1990 , the growth in fossil fuel $\mathrm{CO}_{2}$ emissions has been dominated by countries that do not have emissions limitations in the so-called non-Annex B of the Kyoto Protocol (mostly emerging economies in developing countries), where emissions have more than doubled in that time (Fig. 1b). Among Annex B countries (mostly advanced economies with emissions limitations), growth in some has been offset by declines in others. This recent growth in $\mathrm{CO}_{2}$ emissions parallels a shift in the largest fuel emission source from oil to coal. Coal contributed $40 \%$ of the fossil fuel $\mathrm{CO}_{2}$ emissions in 2008, compared with $37 \%$ for 1990-2000, whereas the contribution of oil changed from $41 \%$ for $1990-2000$ to $36 \%$ in 2008 (Fig. 1c). This shift in the dominant source of fossil fuel emissions has reversed the prevalence of oil since 1968. The growth in emissions since 2000 was also accompanied by an increase in the world per-capita emissions from 1.1 metric tons of carbon in 2000 (Fig. 1d) to an all-time high of 1.3 metric tons of carbon in 2008 .

There is growing evidence that the rapid growth in international trade $^{4-10}$ and a shift of Annex B economic activity towards services ${ }^{8}$ were significant in driving non-Annex $\mathrm{B} \mathrm{CO}_{2}$ emission increases due to fossil fuels. Several recent studies provide indicators of the magnitude and time evolution of the share of non-Annex B emission growth that was due to production of manufactured products exported and consumed in Annex B countries. In 2001, the equivalent of $0.22 \mathrm{Pg} \mathrm{C}$ was emitted in non-Annex B countries to produce internationally traded products consumed in Annex B countries ${ }^{4}$. In China alone, $30 \%$ of the growth in emissions between 1990 and 2002 was attributable to the production of exports from China that were consumed in other countries ${ }^{6}$, and the share of the growth increased to 50\% between 2002 and 2005 (ref. 7). In 1990, $16 \%$ of Chinese emissions were from the production of exports, increasing to $30 \%$ in 2005. Over half of the exported products were destined for Annex B countries ${ }^{6,7}$. Complementary studies in some Annex B countries showed that consumption-based emissions (that is, emissions including imported products from non-Annex B countries, but excluding goods and services) were increasing faster than emissions from domestic production ${ }^{8,9}$. In the UK, for instance, within-country emissions decreased by 5\% between 1992 and 2004, whereas consumption-based emissions increased by $12 \%$ (ref. 8). In the USA, within-country emissions increased by 6\% between 1997 and 2004, whereas consumption-based emissions increased by $17 \%$ (ref. 9). In both cases, a key factor driving the growth in consumption-based emissions was the import of manufactured products from China ${ }^{6-9}$. Taken together, these studies imply that a considerable share of the growth of emissions from non-Annex B countries was associated with international trade. This explained around one-quarter of the growth in non-Annex B emissions since 2000.

The growth in the world gross domestic product (GDP) was a key driver in the recent increase in $\mathrm{CO}_{2}$ emissions ${ }^{2}$. Consequently, 
a

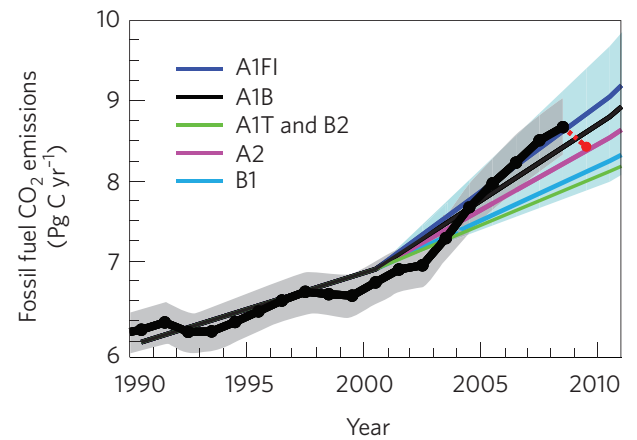

b

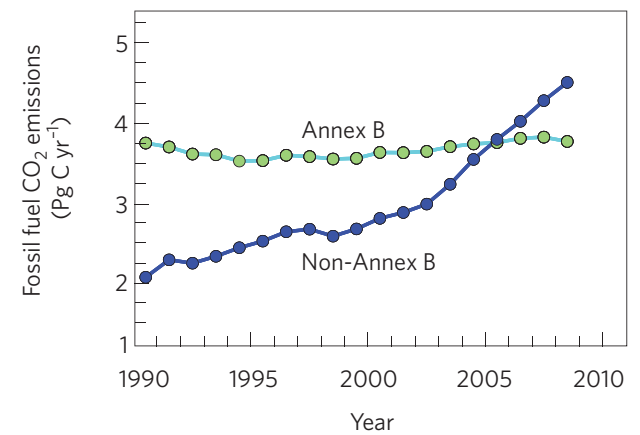

c

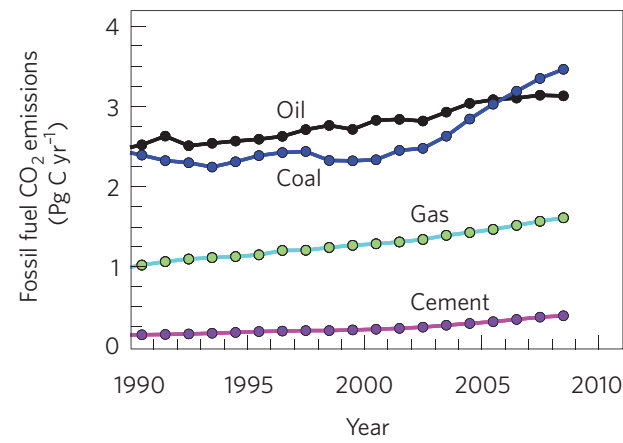

d

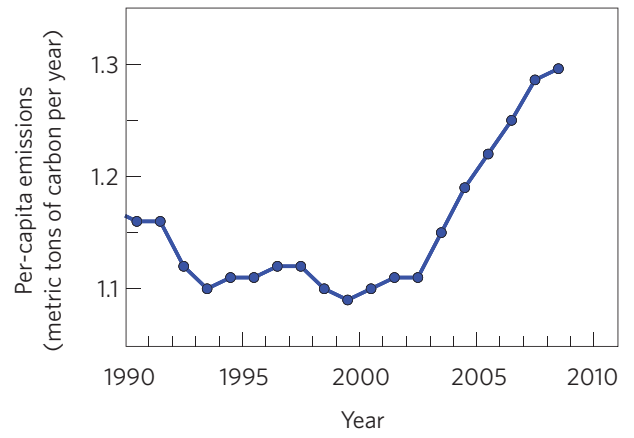

Figure 1 | Fossil fuel $\mathrm{CO}_{2}$ and per-capita emissions since 1990.

a-c, Fossil fuel emissions for the globe (a), Annex B countries (mostly advanced economies; green) and non-Annex B countries (mostly developing countries; blue) (b) and, specifically, coal (blue), oil (black), gas combustion (green) and cement production (purple) (c). The data in all panels are the annual mean data. Panel $\mathbf{a}$ also shows the projections averaged by scenario family from the IPCC Special Report on Emissions Scenarios (full coloured lines ${ }^{3}$ ), as in ref. 2 . The grey shading in $\mathbf{a}$ is the uncertainty in emissions. The blue shading covers all $\mathrm{CO}_{2}$ emissions scenarios used to project climate by the IPCC Fourth Assessment Report. The red dot and dashed line in a are the projected $\mathrm{CO}_{2}$ emissions for 2009 (see text).d, Global per-capita emissions. the global financial crisis that affected markets in 2008 also had an effect on the global $\mathrm{CO}_{2}$ emissions and probably explains the modest growth in emissions of $2.0 \%$ since 2007, compared with the faster than average growth of $3.6 \% \mathrm{yr}^{-1}$ observed for $2000-2007$. We predict a decrease of $2.8 \%$ in global $\mathrm{CO}_{2}$ emissions for 2009 using the change in GDP projected by the International Monetary Fund $(-1.1 \%$ as of October 2009) and assuming that the carbon intensity of world GDP has continued to improve following its long-term trend of $-1.7 \% \mathrm{yr}^{-1}$ (refs 11, 12; Fig. 1a). The abrupt decrease in GDP in 2009 could bring global $\mathrm{CO}_{2}$ emissions back to just below their 2007 level and into the middle range of the emissions scenarios that were used by the IPCC to project climate this century ${ }^{3}$. The evolution of global $\mathrm{CO}_{2}$ emissions after 2009 will depend on the subsequent trends in GDP and on the evolution of the carbon intensity of GDP, for instance as a result of countries following international agreements to curb $\mathrm{CO}_{2}$ emissions.

\section{Land-use change $\mathrm{CO}_{2}$ emissions}

Emissions from LUC are the second-largest anthropogenic source of $\mathrm{CO}_{2}$. Deforestation, logging and intensive cultivation of cropland soils emit $\mathrm{CO}_{2}$. These emissions are partly compensated by $\mathrm{CO}_{2}$ uptake from the regrowth of secondary vegetation and the rebuilding of soil carbon pools following afforestation, abandonment of agriculture (including the fallow phase of shifting cultivation), fire exclusion and the shift to agricultural practices that conserve soil carbon. Unlike fossil fuel emissions, which reflect instantaneous economic activity, LUC emissions are due to both current deforestation and the carry-over effects of $\mathrm{CO}_{2}$ losses from areas deforested in previous years.

Here we have used a revised estimate ${ }^{11}$ of the net $\mathrm{CO}_{2}$ flux resulting from LUC based on United Nations data for LUC areas (available until 2005) and a book-keeping method ${ }^{13}$. For the period 1990-2005, net LUC $\mathrm{CO}_{2}$ emissions were 1.5 $\pm 0.7 \mathrm{Pg} \mathrm{C} \mathrm{yr}^{-1}$, and were dominated by tropical deforestation. In the deforestation process, fire is the primary means by which forests are converted to pastures or croplands ${ }^{14}$, after timber exploitation. To estimate LUC emissions after 2005, we used emissions due to fire in deforestation areas ${ }^{15}$ as a proxy for deforestation emissions (Methods).

In 2008, the fire emissions associated with deforestation were $0.3 \mathrm{Pg} \mathrm{C} \mathrm{yr}^{-1}$ less than their 1997-2008 average of $0.7 \mathrm{Pg} \mathrm{C} \mathrm{yr}^{-1}$, with the largest reductions being in southeast Asia $(-65 \%)$ and tropical America $(-40 \%)$. Lower-than-average deforestation rates reported in the Brazilian Amazon rainforest ${ }^{16}$ corroborate lower LUC emissions in 2008 in tropical America. Combining the long-term average global LUC flux, 1.5 $\mathrm{Pg} \mathrm{C} \mathrm{yr}^{-1}$, with the 2008

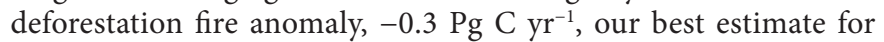
2008 LUC emissions is $1.2 \mathrm{Pg} \mathrm{C} \mathrm{yr}^{-1}$. Wet La Niña conditions in 2008 probably limited fire use and deforestation rates in southeast Asia, particularly in Indonesia ${ }^{17}$. In the Amazon basin, climate conditions were not anomalous, suggesting that other factors caused the decrease in 2008 deforestation rates, which for the Brazilian Amazon rainforest was the continuation of a decreasing trend following high deforestation rates in 2002-2004 (ref. 16).

Taken together, the total $\mathrm{CO}_{2}$ emission from fossil fuel combustion and LUC was $9.9 \pm 0.9 \mathrm{Pg} \mathrm{C} \mathrm{yr}^{-1}$ in 2008. The relative contribution of $\mathrm{LUC} \mathrm{CO}_{2}$ emissions to total anthropogenic $\mathrm{CO}_{2}$ emissions decreased from $20 \%$ in $1990-2000$ to $12 \%$ in 2008 , owing to increasing fossil fuel emissions and below-average deforestation emissions in 2008. Although LUC emissions were the smaller factor, their uncertainty, $\pm 0.7 \mathrm{Pg} \mathrm{C} \mathrm{yr}^{-1}$, is larger than the uncertainty of $\pm 0.5 \mathrm{Pg} \mathrm{C} \mathrm{yr}^{-1}$ associated with fossil fuel emissions (Methods).

\section{Atmospheric $\mathrm{CO}_{2}$ growth and $\mathrm{CO}_{2}$ sinks}

On average, $43 \%$ of the total $\mathrm{CO}_{2}$ emissions each year between 1959 and 2008 remained in the atmosphere, but this fraction is 
subject to very large year-to-year variability (Fig. 2a). This 'airborne fraction' increased on average by $0.3 \pm 0.2 \% \mathrm{yr}^{-1}$ between 1959 and 2008. There is a $90 \%$ probability that this increasing trend is significant taking into account the background variability (Methods). The trend and its significance are sensitive to estimates of LUC emissions, which have large uncertainties. We quantified the impact of LUC uncertainty on the airborne-fraction trend using a range of LUC estimates (Supplementary Information). For all nine published LUC estimates considered, the trend in the airborne fraction was positive with a significance level at or above $90 \%$. We conclude that a positive trend in the airborne fraction is 'likely' (66\% confidence interval), according to the terminology developed by the IPCC ${ }^{18}$.

A positive trend in the airborne fraction could be explained by several factors. First, the atmospheric $\mathrm{CO}_{2}$ concentration could be increasing on a timescale shorter than those regulating the rate of uptake of carbon sinks. Second, both the land and ocean $\mathrm{CO}_{2}$ sinks are expected to decrease in efficiency at high ambient $\mathrm{CO}_{2}$ concentration because of the limits of $\mathrm{CO}_{2}$ fertilization on land and the decrease in carbonate concentration, which buffers $\mathrm{CO}_{2}$ in the ocean ${ }^{19}$. Third, the land and/or ocean $\mathrm{CO}_{2}$ sink could be responding to climate variability and change. Finally, sink processes not considered in current models may be contributing to the observed changes ${ }^{19}$.

Combined evidence from atmosphere and ocean observations constrains the mean uptake rates of land and ocean $\mathrm{CO}_{2}$ sinks to 2.6 \pm 0.7 and 2.2 $\pm 0.4 \mathrm{Pg} \mathrm{C} \mathrm{yr}^{-1}$ for 1990-2000, respectively ${ }^{11,19-22}$. We estimated the year-to-year variability and trends in the land and ocean $\mathrm{CO}_{2}$ sinks using a series of global models that represent the complex processes governing the carbon cycle in these two pools (Methods). The models were forced by observed changes in global atmospheric $\mathrm{CO}_{2}$ concentration and by variable climate fields.

For 2008, the models estimated that the uptake rates for land and ocean $\mathrm{CO}_{2}$ sinks were $4.7 \pm 1.2$ and $2.3 \pm 0.4 \mathrm{Pg} \mathrm{C} \mathrm{yr}^{-1}$, respectively. The land $\mathrm{CO}_{2}$ sink was larger (in terms of uptake rate) and the ocean $\mathrm{CO}_{2}$ sink was smaller in 2008, relative to the previous three years (Fig. 2), because the El Niño/Southern Oscillation (ENSO) was in a positive (La Niña) state in 2008. During La Niña conditions, the land $\mathrm{CO}_{2}$ sink is enhanced owing to lower temperatures and wetter conditions in the tropics, whereas the ocean $\mathrm{CO}_{2}$ sink is reduced owing to more intense equatorial upwelling of carbon-rich waters. Observations in the equatorial Pacific Ocean corroborate the lower ocean $\mathrm{CO}_{2}$ sink in 2008 (ref. 23) estimated by the models. The ocean models also attributed the low ocean $\mathrm{CO}_{2}$ sink in 2008 in part to a weaker Southern Ocean sink, in response to the continuing increase in the southern annular mode ${ }^{24,25}$. The model results over 1980-2006 were broadly consistent with the results from atmospheric inverse models, which estimate the regional distribution of air-surface $\mathrm{CO}_{2}$ fluxes using the spatiotemporal variability in atmospheric $\mathrm{CO}_{2}$ concentration measurements ${ }^{26,27}$ (Supplementary Information).

The land biosphere models showed an increasing global land $\mathrm{CO}_{2}$ sink between 1959 and 2008 (Fig. 2c), with large year-toyear variability. The variability was primarily driven by variability in precipitation, surface temperature and radiation ${ }^{28-30}$. During 1959-2008, the fraction of the total $\mathrm{CO}_{2}$ emissions that was absorbed by the land had no significant global trend. The ocean models showed an increasing global ocean $\mathrm{CO}_{2}$ sink between 1959 and 2008 (Fig. 2d), with small year-to-year variability compared with the land sink. The modelled $\mathrm{CO}_{2}$ sink increased at a lower rate than the emissions, and the fraction of the total $\mathrm{CO}_{2}$ emissions that was absorbed by the oceans decreased by $0.60 \pm 0.15 \% \mathrm{yr}^{-1}$ (Supplementary Table 1 ) as a result. The long-term decrease in the fraction of the emissions taken up by the oceans cannot be verified from ocean observations alone because of the lack of global data coverage ${ }^{31}$. However, a

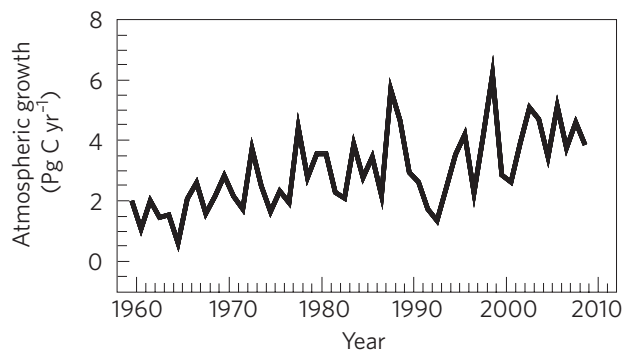

b

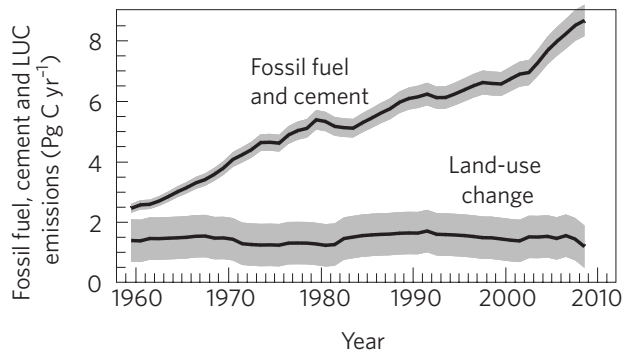

c

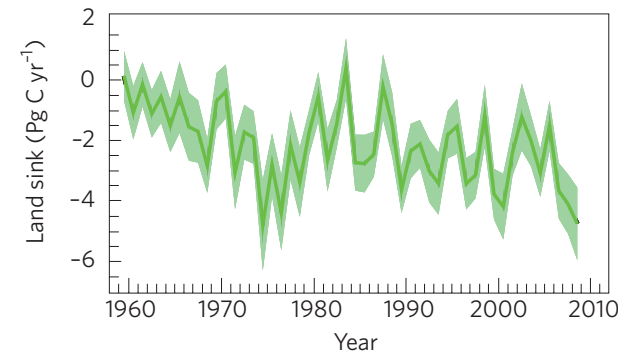

d

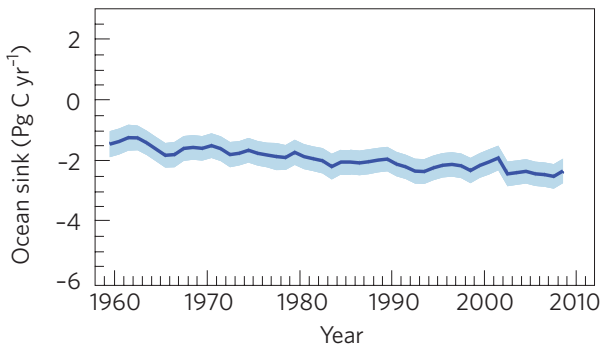

e

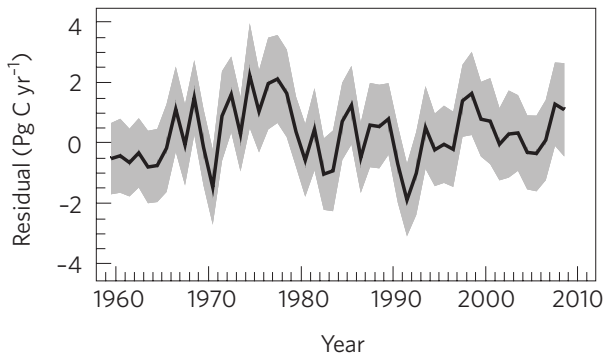

Figure 2 | Components of the global $\mathbf{C O}_{\mathbf{2}}$ budget. a, The atmospheric $\mathrm{CO}_{2}$ growth rate. $\mathbf{b}, \mathrm{CO}_{2}$ emissions from fossil fuel combustion and cement production, and from LUC. c, Land $\mathrm{CO}_{2}$ sink (negative values correspond to land uptake). d, Ocean $\mathrm{CO}_{2}$ sink (negative values correspond to ocean uptake). e, The residual sum of all sources and sinks. The land and ocean sinks $(\mathbf{c}, \mathbf{d})$ are shown as an average of several models normalized to the observed mean land and ocean sinks for 1990-2000 (refs 11,19). The shaded area is the uncertainty associated with each component. See Methods for the sources of data and an explanation of uncertainties. 


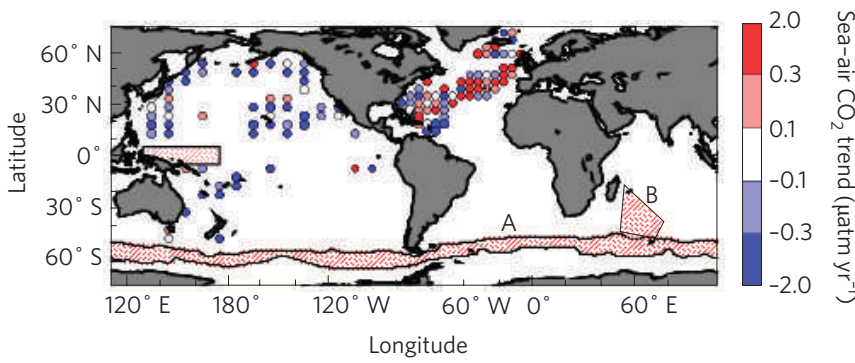

Figure 3 | Trends in the observed partial pressure of $\mathrm{CO}_{2}$ for ocean minus air, for 1981-2007. The observed trends are calculated by fitting a linear trend to repeated measurements of surface-ocean and air $\mathrm{CO}_{2}$ as in refs 31 and 32. Positive (red) values indicate regions where the partial pressure of $\mathrm{CO}_{2}$ in the ocean is increasing faster than atmospheric $\mathrm{CO}_{2}$. Large, medium and small dots are plotted for trends with errors of $<0.25,0.25-0.50$ and $>0.50 \mu$ atm $\mathrm{yr}^{-1}$, respectively. In southern circumpolar waters (A), the trends were estimated from austral winter data $^{31}$. In the South Indian Ocean (B), the trends were estimated for 1991-2007 (ref. 34) only.

a weakening of the regional $\mathrm{CO}_{2}$ sinks has been observed since at least 1990 (Fig. 3), from repeated surface-ocean $\mathrm{CO}_{2}$ observations in the North Atlantic Ocean ${ }^{32,33}$ and in the Southern Ocean ${ }^{31,34}$, and from the spatial distribution of atmospheric $\mathrm{CO}_{2}$ increases in the Southern Ocean ${ }^{24}$. These observations suggest that in some ocean regions, the ocean carbon cycle is responding to climate variability and climate change in a way that can affect the net uptake of $\mathrm{CO}_{2}$ by the ocean. In contrast, increasing air-sea $\mathrm{CO}_{2}$ flux was observed in the North Pacific Ocean ${ }^{35}$.

We identified the drivers of the trends in land and ocean $\mathrm{CO}_{2}$ sinks in the models by forcing a subset of the models with increasing atmospheric $\mathrm{CO}_{2}$ concentration alone (no changes in climate; see Supplementary Information). These additional simulations isolate the effect of climate from the combined effects of rapidly rising $\mathrm{CO}_{2}$ and high ambient $\mathrm{CO}_{2}$ concentration. In all models tested, the land and ocean $\mathrm{CO}_{2}$ sinks increased at the same rate (in one model) or faster (in six models) when climate did not change. We combined the land and ocean $\mathrm{CO}_{2}$ sinks estimated by the models with the emissions to reproduce the time evolution of the airborne fraction. The model-based airborne fraction decreased at a rate of $0.8 \% \mathrm{yr}^{-1}$ when the models were forced by increasing $\mathrm{CO}_{2}$ concentration alone, and increased at a rate of $0.1 \% \mathrm{yr}^{-1}$ (close to the rate of $0.3 \% \mathrm{yr}^{-1}$ estimated from observations) when the models were forced by both increasing $\mathrm{CO}_{2}$ concentration and changes in climate. These simulations do not completely exclude a role for rapidly rising $\mathrm{CO}_{2}$ or high ambient $\mathrm{CO}_{2}$ concentration because the models are subject to uncertainty, particularly due to their coarse resolution ${ }^{36}$ in the ocean and to errors in observed precipitation and radiation on land.

Our estimates of sources and sinks of $\mathrm{CO}_{2}$ were based on largely independent data and methods. Thus, when all the sources and sinks were summed every year they did not necessarily add to zero, because of the errors in the various methods. The sum of all $\mathrm{CO}_{2}$ sources and sinks, which we call the 'residual', spanned a range

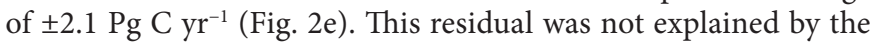
atmospheric $\mathrm{CO}_{2}$ growth rate, the $\mathrm{CO}_{2}$ emissions from fossil fuel combustion or the ocean uptake, because the uncertainties in these components were much smaller than the variability of the residual. Errors in LUC flux may explain a small part of the residual, for instance during the late 1990s, when fires in Indonesia were partly caused by land clearance taking advantage of the drought conditions ${ }^{17}$. Our fire-based LUC anomalies for 1997 were 0.7 Pg C greater than normal and account for one-half of the residual for that year. Overall, the residual was most probably caused by the regional responses of terrestrial vegetation to climate variability, indicating that land models overestimated the response of vegetation to the relatively cool/wet La Niña-like climatic conditions of the mid 1970s and underestimated the response to the volcanic eruption of Mount Pinatubo, in the Philippines, in the early 1990s. This later underestimation has been explained elsewhere as resulting from a missing response in the models to the aerosolinduced increase in the diffuse-light component of surface irradiance, and the subsequent enhancement of light penetration into vegetation canopies ${ }^{29}$.

As a result of all $\mathrm{CO}_{2}$ sources and sinks, atmospheric $\mathrm{CO}_{2}$ growth

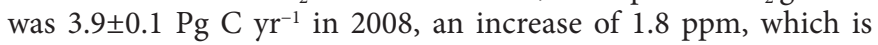
$0.6 \mathrm{Pg} \mathrm{C} \mathrm{yr}^{-1}$ less than the average of the previous three years despite there being an increase in $\mathrm{CO}_{2}$ emissions from fossil fuel combustion. Average atmospheric $\mathrm{CO}_{2}$ in 2008 reached a concentration of 385 ppm, which is $38 \%$ above pre-industrial levels. The lower-thanaverage atmospheric growth rate was probably driven by a high land $\mathrm{CO}_{2}$ uptake due to the La Niña state of ENSO, and by reduced rates of deforestation in southeast Asia and in the Amazon ${ }^{16}$, as indicated by lower rates of fire and clear-cut activities measured at the deforestation frontier.

\section{Filling the gaps in the global $\mathrm{CO}_{2}$ budget}

Progress has been made in monitoring the trends in the carbon cycle and understanding their drivers. However, major gaps remain, particularly in our ability to link anthropogenic $\mathrm{CO}_{2}$ emissions to atmospheric $\mathrm{CO}_{2}$ concentration on a year-to-year basis; this creates a multi-year delay and adds uncertainty to our capacity to quantify the effectiveness of climate mitigation policies. To fill this gap, the residual $\mathrm{CO}_{2}$ flux from the sum of all known components of the global $\mathrm{CO}_{2}$ budget needs to

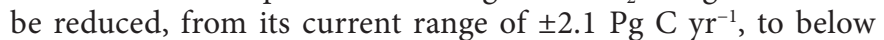
the uncertainty in global $\mathrm{CO}_{2}$ emissions, $\pm 0.9 \mathrm{Pg} \mathrm{C} \mathrm{yr}^{-1}$. If this can be achieved with improvements in models and observing systems, geophysical data could provide constraints on global $\mathrm{CO}_{2}$ emissions estimates.

The likely recent trend in the airborne fraction of the total emissions suggests that the growth in uptake rate of $\mathrm{CO}_{2}$ sinks is not keeping up with the increase in $\mathrm{CO}_{2}$ emissions ${ }^{11}$. The models used here indicate that this trend could be due to the response of the land and ocean $\mathrm{CO}_{2}$ sinks to climate variability and climate change. If the model response to recent changes in climate is correct, this would lend support to the positive feedback between climate and the carbon cycle that was predicted by many coupled climate-carbon cycle models ${ }^{37}$. However, these models do not yet include many processes and reservoirs that may be important, such as peat, buried carbon in permafrost soils, wild fires, ocean eddies and the response of marine ecosystems to ocean acidification. An improved knowledge of regional trends would help to constrain the climate-carbon cycle feedback better.

The current growth in global anthropogenic $\mathrm{CO}_{2}$ emissions is tightly linked to the growth in GDP. On the basis of the projected changes in GDP, it is likely that $\mathrm{CO}_{2}$ emissions in 2009 will revert to their 2007 levels. The key to sustained emissions reductions after the global economy recovers lies in restructuring the primary energy use to decouple emissions from GDP ${ }^{12}$.

\section{Methods}

Original data to complete the global $\mathrm{CO}_{2}$ budget are generated by multiple agencies and research groups around the world and are collated annually by the Global Carbon Project (http://www.globalcarbonproject.org). $\mathrm{CO}_{2}$ emissions from fossil fuel and other industrial processes between 1959 and 2006 were based on United Nations Energy Statistics and cement data from the US Geological Survey ${ }^{38}$, and were provided by the Carbon Dioxide Information Analysis Center. For 2007 and 2008 , increases in fossil fuel emissions were calculated using BP energy data ${ }^{39,40}$ and increases in cement emissions were based on the preliminary data ${ }^{41}$ on 20 of the largest producers (amounting to over $80 \%$ of total global production), assuming 
the same fractional change as in 2005-2006 for smaller producers. The gas-flaring emissions for 2006 were also used for 2007 and 2008. Per-capita emissions were compiled by the Carbon Dioxide Information Analysis Center between 1959 and 2006. For 2007 and 2008, per-capita emissions were based on our global $\mathrm{CO}_{2}$ emissions and world population from the US Census Bureau. We used an uncertainty in $\mathrm{CO}_{2}$ emissions of $\pm 6 \%$ (ref. 42 ), representing a $1 \sigma(66 \%$ ) confidence interval. This uncertainty was revised upwards from the $5 \%$ used in ref. 11 beccause of the larger share of global emissions from non-Annex B countries.

We calculated $\mathrm{CO}_{2}$ emissions from LUC using a book-keeping method ${ }^{13}$ with the revised statistical data from the Food and Agriculture Organization of the United Nations Global Forest Resource Assessment ${ }^{43}$, as in ref. 11. We used fire emissions estimates from the Oak Ridge National Laboratory Distributed Active Archive Center's Global Fire Emissions Database, version 2, where information on burned area and fire activity from various satellite sensors ${ }^{44}$ is combined with a biogeochemical model to estimate carbon stocks and combustion parameters ${ }^{45}$. We sampled only those $1^{\circ} \times 1^{\circ}$ grid cells undergoing active deforestation during the 2000-2005 period, using existing maps ${ }^{46}$. Emissions from the 'maintenance fires' (for example pasture burning) at the deforestation frontier are probably an order of magnitude lower than deforestation emissions because of lower fuel loads in pasture and cropland ecosystems $\mathrm{s}^{45}$; in our analyses, we therefore included $90 \%$ of the total estimated emissions. The use of fire estimates assumes that year-to-year changes in fire $\mathrm{CO}_{2}$ emissions were the main cause of interannual variability in LUC emissions and that the delayed emissions from decomposition were relatively constant. The variability in LUC estimated from fire emissions correlated with the variability estimated by the book-keeping method when they overlap (correlation coefficient, $r=0.54 ; n=12$ ). We used an uncertainty of $\pm 0.7 \mathrm{Pg} \mathrm{C} \mathrm{yr}^{-1}$, representing a $1 \sigma(66 \%)$ confidence interval. This uncertainty was revised upwards from the $\pm 0.5 \mathrm{Pg} \mathrm{C} \mathrm{yr}^{-1}$ used in ref. 11, to acknowledge recently identified inconsistencies between deforestation and agricultural conversion statistics (see Supplementary Information).

The data on annual growth in atmospheric $\mathrm{CO}_{2}$ concentration was provided by the US National Oceanic and Atmospheric Administration Earth System Research Laboratory (http://www.esrl.noaa.gov/gmd/ccgg/trends). We used the global mean data after 1980 and the Mauna Loa data between 1959 and 1980. The land $\mathrm{CO}_{2}$ sink was estimated using five global vegetation models updated from ref. 28 (see Supplementary Information). The models represent the processes governing ecosystem carbon dynamics in biomass, litter and soil pools and the space-time distribution of $\mathrm{CO}_{2}$ fluxes exchanged with the overlying atmosphere. All models were forced by observed atmospheric $\mathrm{CO}_{2}$ concentration and a combination of meteorological fields from the Climatic Research Unit observed climate data and the US National Centers for Environmental Prediction reanalysis product ${ }^{47}$. The ocean $\mathrm{CO}_{2}$ sink was estimated using four ocean general circulation models coupled to ocean biogeochemistry models ${ }^{24,48-50}$. The models represent the physical, chemical and biological processes governing the marine carbon cycle and the space-time distribution of $\mathrm{CO}_{2}$ fluxes exchanged with the overlying atmosphere. All models were forced by meteorological fields from the US National Centers for Environmental Prediction reanalysis product ${ }^{47}$. The land and ocean $\mathrm{CO}_{2}$ sinks were estimated from the mean of all models. We corrected the model mean to agree with the observed uptake rates for land and ocean $\mathrm{CO}_{2}$ sinks in 1990-2000 (refs 11,19). Thus, the models were used to assess the year-to-year variability and trends in the land and ocean $\mathrm{CO}_{2}$ sinks only. The uncertainty for a given time period combined the uncertainty for 1990-2000 (ref. 19) and \pm 1 mean absolute deviation for all models around the central model estimate for the given period (see Supplementary Information)

The significance of the trend in airborne fraction was computed from the monthly deseasonalized atmospheric $\mathrm{CO}_{2}$ data as detailed in ref. 11. The noise in the airborne fraction was reduced by removing the part of the variability associated with the ENSO and volcanic-activity indices. The statistical significance was computed from a 1,000-member Monte Carlo simulation with noise properties similar to those of the airborne fraction. The standard deviation of the 1,000 -member simulation provided the uncertainty in the results.

\section{References}

1. Conway, T. J. et al. Evidence of interannual variability of the carbon cycle from the NOAA/CMDL global air sampling network. J. Geophys. Res. 99, 22831-22855 (1994).

2. Raupach, M. et al. Global and regional drivers of accelerating $\mathrm{CO}_{2}$ emissions. Proc. Natl Acad. Sci. USA 104, 9913-9914 (2007).

3. Nakicenovic, N. \& Swart, R. Special Report on Emissions Scenarios (Cambridge Univ. Press, 2000).

4. Peters, G. P. \& Hertwich, E. G. $\mathrm{CO}_{2}$ embodied in international trade with implications for global climate policy. Environ. Sci. Technol. 42, 1401-1407 (2008)

5. Peters, G. P. et al. Trade, transport, and sinks extend the carbon dioxide responsibility of countries. Climatic Change doi:10.1007/s10584-009-9606-2 (2009).

6. Weber, C. L., Peters, G. P., Guan, D. \& Hubacek, K. The contribution of Chinese exports to climate change. Energ. Policy 36, 3572-3577 (2008)
7. Guan, D., Peters, G. P., Weber, C. L. \& Hubacek, K. Journey to world top emitter: an analysis of the driving forces of China's recent $\mathrm{CO}_{2}$ emissions surge. Geophys. Res. Lett. 36, L04709 (2009).

8. Minx, J. C., Baiocchi, G., Wiedmann, T. \& Barrett, J. Understanding Changes in UK $\mathrm{CO}_{2}$ Emissions 1992-2004: A Structural Decomposition Analysis (UK Department for Environment, Food and Rural Affairs, 2009).

9. Weber, C. \& Matthews, H. S. Embodied environmental emissions in US international trade, 1997-2004. Environ. Sci. Technol. 41, 4875-4881 (2007)

10. Hertwich, E. G. \& Peters, G. P. The carbon footprint of nations - a global, trade-linked analysis. Environ. Sci. Technol. 43, 6414-6420 (2009).

11. Canadell, J. G. et al. Contributions to accelerating atmospheric $\mathrm{CO}_{2}$ growth from economic activity, carbon intensity, and efficiency of natural sinks. Proc. Natl Acad. Sci. USA 104, 18866-18870 (2007).

12. Raupach, M. R., Canadell, J. G. \& Le Quéré, C. Anthropogenic and biophysical contributions to increasing atmospheric $\mathrm{CO}_{2}$ growth rate and airborne fraction. Biogeosciences 5, 1601-1613 (2008).

13. Houghton, R. A. Revised estimates of the annual net flux of carbon to the atmosphere from changes in land use and land management 1850-2000 Tellus B 55, 378-390 (2003).

14. Mouillot, F. C. \& Field, B. Fire history and the global carbon budget: a $1^{\circ} \times 1^{\circ}$ fire history reconstruction for the 20th century. Glob. Change Biol. 11, 398-420 (2005).

15. van der Werf, G. R. et al. Interannual variability in global biomass burning emissions from 1997 to 2004. Atmos. Chem. Phys. 6, 3423-3441 (2006).

16. Instituto Nacional de Pesquisas Espaciais. PRODES: Assessment of Deforestation in Brazilian Amazonia $<$ http://www.obt.inpe.br/prodes/index.html> (2009).

17. van der Werf, G. R. et al. Climate regulation of fire emissions and deforestation in equatorial Asia. Proc. Natl Acad. Sci. USA 105, 20350-23055 (2008).

18. IPCC Climate Change 2007: The Physical Science Basis (eds Solomon, S. et al.) 1-18 (Cambridge Univ. Press, 2007).

19. Denman, K. L. et al. in IPCC Climate Change 2007: The Physical Science Basis (eds Solomon, S. et al.) 499-587 (Cambridge Univ. Press, 2007).

20. Manning, A. C. \& Keeling, R. F. Global oceanic and land biotic carbon sinks from the Scripps atmospheric oxygen flask sampling network. Tellus $B$ 58, 95-116 (2006).

21. McNeil, B. I., Matear, R. J., Key, R. M., Bullister, J. L. \& Sarmiento, J. L. Anthropogenic $\mathrm{CO}_{2}$ uptake by the ocean based on the global chlorofluorocarbon data set. Science 299, 235-239 (2003).

22. Gruber, N. et al. Oceanic sources, sinks, and transport of atmospheric $\mathrm{CO}_{2}$ Glob. Biogeochem. Cycles 23, GB1005 (2009).

23. Feely, R. A. et al. Decadal variability of the air-sea $\mathrm{CO}_{2}$ fluxes in the equatorial Pacific Ocean. J. Geophys. Res. 111, C07S03 (2006).

24. Le Quéré, C. et al. Saturation of the Southern Ocean $\mathrm{CO}_{2}$ sink due to recent climate change. Science 316, 1735-1738 (2007).

25. Lenton, A. et al. Stratospheric ozone depletion reduces ocean carbon uptake and enhances ocean acidification. Geophys. Res. Lett. 36, L12606 (2009).

26. Gurney, K. R. et al. Towards robust regional estimates of $\mathrm{CO}_{2}$ sources and sinks using atmospheric transport models. Nature 415, 626-630 (2002)

27. Rödenbeck, C., Houweling, S., Gloor, M. \& Heimann, M. $\mathrm{CO}_{2}$ flux history 1982-2001 inferred from atmospheric data using a global inversion of atmospheric transport. Atmos. Chem. Phys. 3, 1919-1964 (2003).

28. Sitch, S. et al. Evaluation of the terrestrial carbon cycle, future plant geography and climate-carbon cycle feedbacks using five dynamic global vegetation models (DGVMs). Glob. Change Biol. 14, 2015-2039 (2008)

29. Mercado, L. M. et al. Impact of changes in diffuse radiation on the global land carbon sink. Nature 458, 1014-1017 (2009).

30. Peylin, P. et al. Multiple constraints on regional $\mathrm{CO}_{2}$ flux variations over land and oceans. Glob. Biogeochem. Cycles 19, GB1011 (2005).

31. Takahashi, T. et al. Climatological mean and decadal changes in surface ocean p $\mathrm{CO}_{2}$, and net sea-air $\mathrm{CO}_{2}$ flux over the global oceans. Deep-Sea Res. II 56, 554-577 (2009)

32. Schuster, U. et al. Trends in North Atlantic sea surface $\mathrm{pCO}_{2}$ from 1990 to 2006. Deep-Sea Res. II 56, 620-629 (2009).

33. Corbière, A., Metzl, N., Reverdin, G., Brunet, C. \& Takahashi, T. Interannual and decadal variability of the oceanic carbon sink in the North Atlantic subpolar gyre. Tellus B 59, 168-179 (2007).

34. Metzl, N. Decadal increase of oceanic carbon dioxide in Southern Indian surface ocean waters (1991-2007). Deep-Sea Res. II 56, 607-619 (2009)

35. Takahashi, T., Sutherland, S. C., Feely, R. A. \& Wanninkhof, R. Decadal change of the surface water $\mathrm{pCO}_{2}$ in the North Pacific: a synthesis of 35 years of observations. J. Geophys. Res. 111, C07S05 (2006).

36. Böning, C. W., Dispert, A., Visbeck, M., Rintoul, S. \& Schwarzkopf, F. U. The response of the Antarctic Circumpolar Current to recent climate change. Nature Geosci. 1, 864-869 (2008). 
37. Friedlingstein, P. et al. Climate-carbon cycle feedback analysis: results from the $\mathrm{C}^{4}$ MIP model intercomparison. J. Clim. 19, 3337-3353 (2006).

38. Van Oss, H. G. in 2006 Minerals Yearbook 16.1-16.36 (US Geological Survey, October 2008).

39. BP Statistical Review of World Energy <http://www.bp.com/productlanding.do? categoryId=6929\&contentId=7044622> (2009).

40. Myhre, G., Alterskjaer, K. \& Lowe, D. A fast method for updating global fossil fuel carbon dioxide emissions. Environ. Res. Lett. 4, 034012 (2009).

41. Van Oss, H. G. in Mineral Commodities Summaries 40-41 (US Geological Survey, 2009).

42. Marland, G. Uncertainties in accounting for $\mathrm{CO}_{2}$ from fossil fuels. J. Ind. Ecol. 12, 136-139 (2008).

43. Food and Agriculture Organization of the United Nations. Global Forest Resource Assessment 2005 FAO Forestry Paper 147, 129-147 (2006).

44. Giglio, L., van der Werf, G. R., Randerson, J. T., Collatz, G. J. \& Kasibhatla, P. Global estimation of burned area using MODIS active fire observations. Atmos. Chem. Phys. 6, 957-974 (2006).

45. van der Werf, G. R. et al. Estimates of fire emissions from an active deforestation region in the southern Amazon based on satellite data and biogeochemical modelling. Biogeosciences 6, 235-249 (2009).

46. DeFries, R. S. et al. Carbon emissions from tropical deforestation and regrowth based on satellite observations for the 1980s and 1990s. Proc. Natl Acad. Sci. USA 99, 14256-14261 (2002).

47. Kalnay, E. et al. The NCEP/NCAR 40-year reanalysis project. Bull. Am. Meteorol. Soc. 77, 437-471 (1996).

48. Thomas, H. et al. Changes in the North Atlantic Oscillation influence $\mathrm{CO}_{2}$ uptake in the North Atlantic over the past two decades. Glob. Biogeochem. Cycles 22, GB4027 (2008).

49. Aumont, O. \& Bopp, L. Globalizing results from ocean in situ iron fertilization studies. Glob. Biogeochem. Cycles 20, GB2017 (2006).

50. Galbraith, E. D., Gnanadesikan, A., Dunne, J. P. \& Hiscock, M. R. Regional impacts of iron-light colimitation in a global biogeochemical model. Biogeosci. Discuss. 6, 7517-7564 (2009).

\section{Acknowledgements}

The annual update and analyses of the global carbon budget are a collaborative effort of the Global Carbon Project, a joint project of the Earth System Science Partnership, contributed to by an international consortium of scientists. We thank C. Rödenbeck, A. Mouchet, R. Keeling and N. Gruber for comments on this manuscript, and C. Enright and E. T. Buitenhuis for modelling support. Many of the observations and modelling analyses were supported by funding agencies in the European Union (CARBOOCEAN and the Natural Environment Research Council's QUEST programme), the United States (the National Science Foundation, NASA, the National Oceanic and Atmospheric Administration and the Office of Science of the Department of Energy), Australia and Brazil.

\section{Author contributions}

C.L.Q., M.R.R., J.G.C., G.M., R.A.H., P.C. and P. Friedlingstein conceived and designed the global $\mathrm{CO}_{2}$ budget. G.M. estimated the fossil fuel emissions and G.P.P. estimated the emissions from the production and international trade of goods and services. R.A.H., G.R.v.d.W. and J.T.R. estimated LUC emissions and were helped by J.G.C., J.P.O. and J.I.H. in their interpretation. S.S., N.V., P.C., P. Foster, P. Friedlingstein, C.H., P.E.L., M.R.L., F.I.W. and I.C.P. designed and performed the land model simulations and were helped by S.W.R. in their interpretation. C.L.Q., L.B., S.C.D., J.M. and J.L.S. designed and performed the ocean model simulations. R.A.F., N.M., U.S. and T.T. provided and analysed the ocean $\mathrm{CO}_{2}$ observations, and T.J.C. provided and analysed the atmospheric $\mathrm{CO}_{2}$ observations. K.G. provided updated atmospheric $\mathrm{CO}_{2}$ inversions. M.R.R. and C.L.Q. computed and analysed the trends in sources, sinks and airborne fraction. S.S., P. Friedlingstein and C.L.Q. analysed the residual with the help of all authors. All authors co-wrote the paper.

\section{Additional information}

Supplementary information accompanies this paper on www.nature.com/ naturegeoscience.

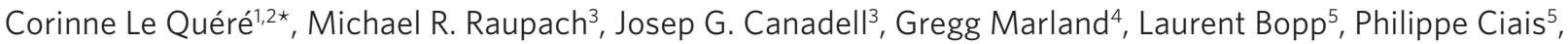
Thomas J. Conway ${ }^{6}$, Scott C. Doney ${ }^{7}$, Richard A. Feely ${ }^{8}$, Pru Foster ${ }^{9}$, Pierre Friedlingstein ${ }^{5,9}$, Kevin Gurney ${ }^{10}$, Richard A. Houghton"1, Joanna I. House ${ }^{9}$, Chris Huntingford ${ }^{12}$, Peter E. Levy ${ }^{13}$, Mark R. Lomas ${ }^{14}$, Joseph Majkut ${ }^{15}$, Nicolas Metz ${ }^{16}$, Jean P. Ometto ${ }^{17}$, Glen P. Peters ${ }^{18}$, I. Colin Prentice ${ }^{9}$, James T. Randerson ${ }^{19}$, Steven W. Running ${ }^{20}$, Jorge L. Sarmiento ${ }^{15}$, Ute Schuster ${ }^{1}$, Stephen Sitch ${ }^{21}$, Taro Takahashi ${ }^{22}$, Nicolas Viovy ${ }^{5}$, Guido R. van der Werf ${ }^{23}$ and F. Ian Woodward ${ }^{14}$

1'School of Environment Sciences, University of East Anglia, Norwich, NR4 7TJ, UK, ${ }^{2}$ British Antarctic Survey, High Cross, Madingley Road, Cambridge BC3 OET, UK, ${ }^{3}$ Global Carbon Project, CSIRO Marine and Atmospheric Research, Canberra, Australian Capital Territory 2601, Australia, ${ }^{4}$ Carbon Dioxide Information Analysis Center, Oak Ridge National Laboratory, Oak Ridge, Tennessee 37831-6335, USA, ${ }^{5}$ Laboratoire des Sciences du Climat et de I'Environnement, UMR 1572 CEA-CNRS-UVSQ, Gif sur Yvette 91191, France, ${ }^{6}$ NOAA Earth System Research Laboratory, Boulder, Colorado 80305, USA, ${ }^{7}$ Woods Hole Oceanographic Institution, Clark 424, MS\#25, Woods Hole, Massachusetts 02543, USA, ${ }^{8}$ Pacific Marine Environmental Laboratory, 7600 Sand Point Way NE, Seattle, Washington 98115, USA, ${ }^{9}$ QUEST, Department of Earth Sciences, University of Bristol, Bristol BS8 1RJ, UK, ${ }^{10}$ Department of Earth and Atmospheric Sciences and Department of Agronomy, Purdue University, Indiana 47907-2051, USA, "Woods Hole Research Center, Falmouth, Massachusetts 02540, USA, ${ }^{12}$ Centre for Ecology and Hydrology, Benson Lane, Wallingford OX10 8BB, UK, ${ }^{13}$ Centre for Ecology and Hydrology, Bush Estate, Penicuik EH26 OQB, UK, ${ }^{14}$ Department of Animal and Plant Sciences, University of Sheffield, Sheffield S10 2TH, UK, ${ }^{15}$ AOS Program, Princeton University, PO Box CN710, Princeton, New Jersey 08544, USA, ${ }^{16}$ LOCEAN-IPSL, CNRS, Institut Pierre Simon Laplace, Université Pierre et Marie Curie, Case 100, 4 Place Jussieu, 75252 Paris Cedex 5, France, ${ }^{17}$ Instituto Nacional de Pesquisas Espaciais, Avenida dos Astronautas 1758, 12227-010, São José dos Campos-SP, Brazil, ${ }^{18} \mathrm{Center}$ for International Climate and Environmental Research - Oslo, PO Box 1129 Blindern, N-0318 Oslo, Norway, ${ }^{19}$ Department of Earth System Science, University of California, Irvine, California 92697, USA, ${ }^{20}$ School of Forestry/Numerical Terradynamic Simulation Group, University of Montana, Missoula, Montana 59812, USA, ${ }^{21}$ School of Geography, University of Leeds, Leeds LS2 9JT, UK, ${ }^{22}$ Lamont-Doherty Earth Observatory of Columbia University, PO Box 1000, 61 Route 9W, Palisades, New York 10964-8000, USA, ${ }^{23}$ Faculty of Earth and Life Sciences, VU University, Amsterdam 1081 HV, Netherlands. *e-mail: c.lequere@uea.ac.uk. 